\title{
Ductile saline ice
}

\author{
G. A. KueHn AND E. M. Schulson \\ Thayer School of Engineering, Dartmouth College, Hanover, New Hampshire 03755, U.S.A.
}

\begin{abstract}
Experiments have shown that tensile ductility of about $5 \%$ or more can be imparted to columnar, saline ice by pre-compressing the material by about $3.5 \%$. This effect is similar to that observed in granular, fresh-water ice and is attributed to the operation of both dislocation creep and diffusion creep within that part of the matrix which recrystallized during the pre-compressive deformation.
\end{abstract}

IT was recently shown that tensile ductility in excess of $25 \%$ can be imparted to granular, fresh-water ice upon slowly pre-compressing the material to the point that dynamic recrystallization begins (Schulson and Kuehn, 1993). This result was surprising and it raised a question about the generality of the effect. This note shows that the phenomenon also occurs in columnar saline ice, although to a lesser degree, and considers a possible implication for first-year sea ice.

The ice was prepared as described by Kuehn and Schulson (1994) and by Smith and Schulson (1994). Its average bulk density and salinity were $909 \pm 3 \mathrm{~kg} \mathrm{~m}^{-3}$ and $4.6 \pm 0.1 \mathrm{ppt}$, respectively, and the grain-size (or average equivalent column diameter) was approximately $5 \mathrm{~mm}$. The $c$ axes were confined more or less to the horizontal plane during growth but randomly oriented within this plane. Cylindrical specimens $(102 \mathrm{~mm}$ diameter $\times 230 \mathrm{~mm}$ ) were cut from the parent puck such that the long axes of the columnar grains were oriented normal to the axis of the cylinder; they were fitted with carpet-backed, synthane end caps following the procedure described by Lee (1986). The specimens were equilibrated at $-10^{\circ} \mathrm{C}$ and then slowly shortened by about $3.5 \%$ by uniaxially compressing along their axis (i.e. across the columnar grains) at a strain rate of about 1 $\times 10^{-5} \mathrm{~s}^{-1}$. Subsequently, the specimens were unloaded. They were then immediately remachined into a dumbbell shape of $67 \mathrm{~mm}$ diameter and $89 \mathrm{~mm}$ gauge length, and then slowly reloaded at $-10^{\circ} \mathrm{C}$ under tension at a strain rate of either $1.3 \times 10^{-6}$ or $1.2 \times 10^{-7} \mathrm{~s}^{-1}$. The time which elapsed between the unloading and the re-loading was about $30 \mathrm{~min}$. During both the pre-compression and the tension steps, the strains were measured using displacement gauges mounted on the ice, as described elsewhere (Kuehn and Schulson, 1994).

The experiment revealed that, like the granular freshwater material, the saline ice also was more ductile upon pre-compressing. One specimen, strained in tension at 1.3 $\times 10^{-6} \mathrm{~s}^{-1}$, elongated $5.5 \%$ before breaking. Its fracture surface had a somewhat granular appearance (Fig. 1). Two other specimens, strained at the lower rate of $1.2 \times$ $10^{-7} \mathrm{~s}^{-1}$, elongated by $5.0 \%$ and by $11.6 \%$ without breaking. In comparison, virgin material of the same origin and at the same temperature elongated by only about $0.5 \pm 0.2 \%$ and broke more cleanly when pulled at a strain rate of $1 \pm 10^{-7} \mathrm{~s}^{-1}$ (Kuehn and others, 1990). In all cases, the specimens deformed without necking, again reflecting the behavior of the fresh-water ice.

Although more ductile, the pre-compressed ice was not weaker. The specimen that broke reached a peak tensile stress of $0.27 \mathrm{MPa}$ at a strain of about $1 \%$; it then softened upon further straining. The other two specimens

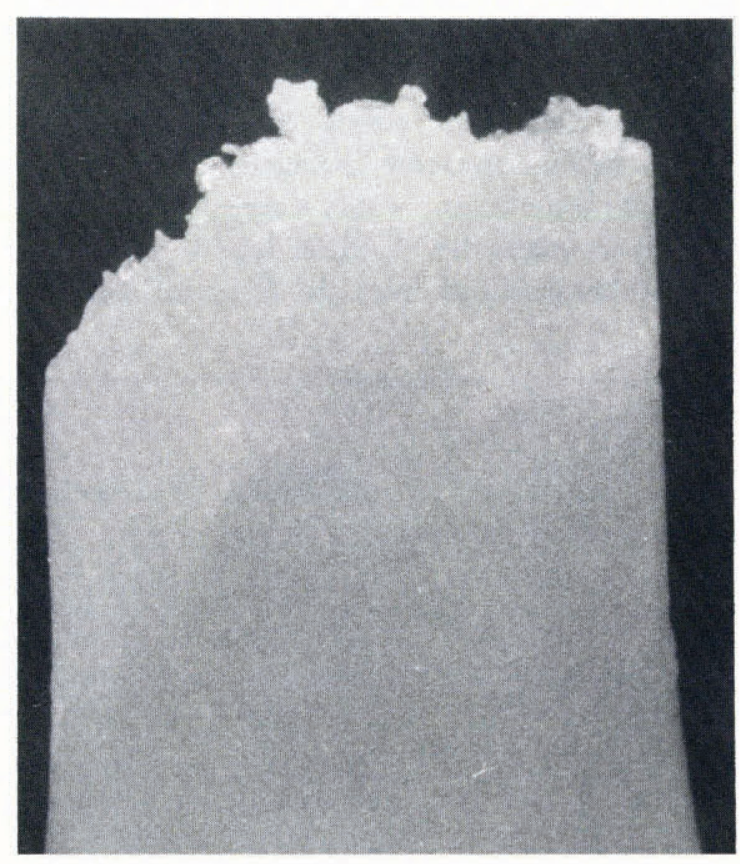

Fig. 1. Photograph showing a broken specimen of columnar, saline ice which had been pre-compressed by about $3.5 \%$ at $-10^{\circ} \mathrm{C}$ at $\approx 10^{-5} \mathrm{~s}^{-1}$ and then strained in tension by $5.5 \%$ at $-10^{\circ} \mathrm{C}$ at $1.3 \times 10^{-6} \mathrm{~s}^{-1}$. Note the absence of necking and the fibrous appearance of the fracture surface. The long axes of the columnar grains are perpendicular to the plane of the photograph. The diameter of the columnar grains is about $5 \mathrm{~mm}$. (Scale: diameter of specimen $=67 \mathrm{~mm}$.) 

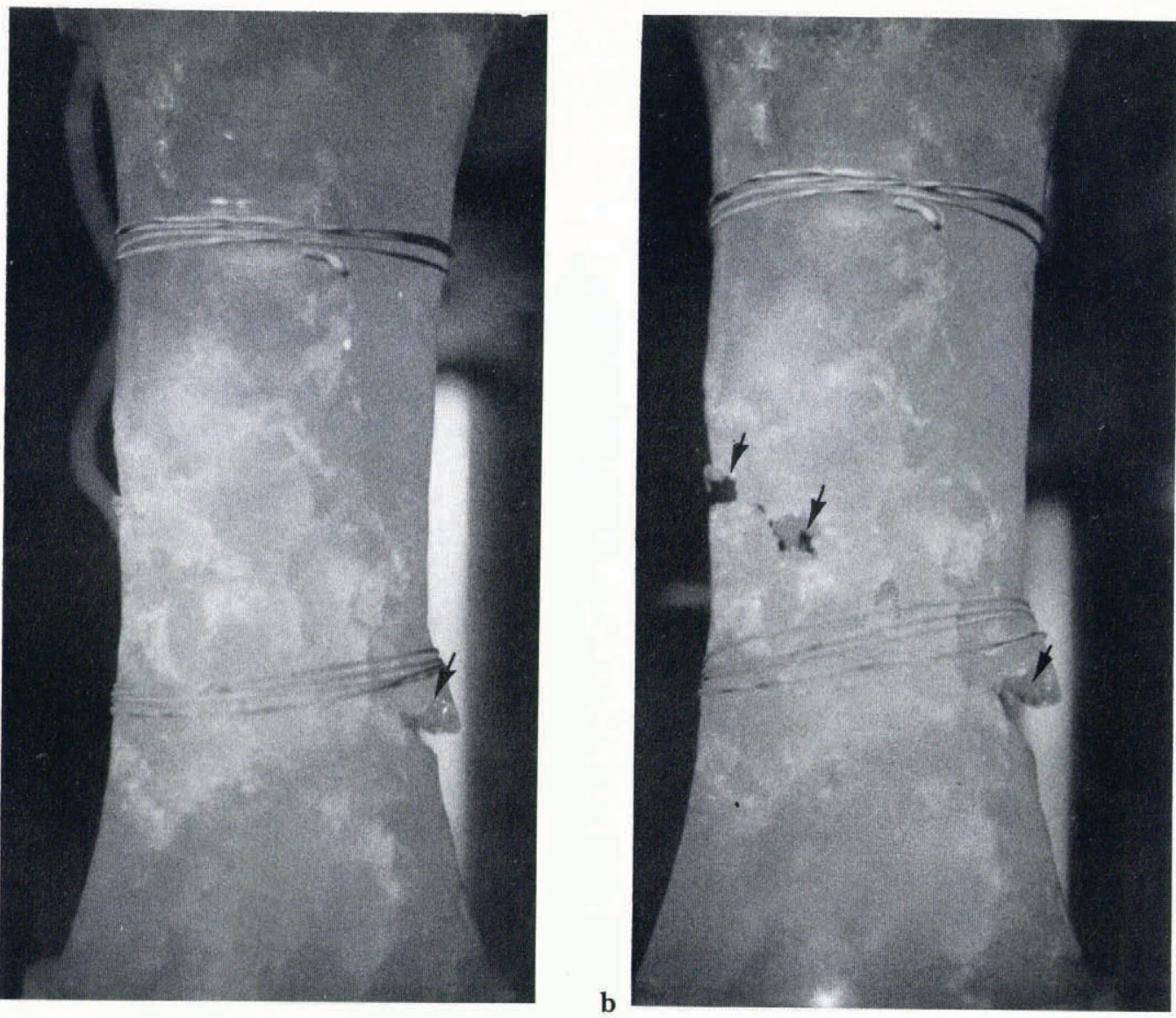

Fig. 2. Photographs showing a specimen of columnar, saline ice after pre-compressing by about $3.5 \%$ at $-10^{\circ} \mathrm{C}$ at $\approx 10^{-5} \mathrm{~s}^{-1}$ and then deforming in tension at $-10^{\circ} \mathrm{C}$ at $1.2 \times 10^{-7} \mathrm{~s}^{-1}:(a)$ after an elongation of $7.3 \% ;(b)$ after an elongation of $11.6 \%$. Note the cracks (arrowed). The long axes of the columnar grains are perpendicular to the plane of the photographs. The rubber bands were used to hold the displacement gauge to the specimen. (Scale: diameter of specimen $=67 \mathrm{~mm}$.)

reached a peak stress of $0.25 \mathrm{MPa}$ at similar strains and then softened. These strengths compare favorably with a peak tensile stress of $0.28 \pm 0.05 \mathrm{MPa}$ for the virgin material (Kuehn and others, 1990).

Interestingly, the pre-compressed specimen which elongated $11.6 \%$ without breaking developed large, void-like cracks (Fig. 2). The voids grew along a shear plane as the specimen lengthened. Presumably, they would have linked up to cause complete fracture had the ice been strained further. This feature was not seen in the virgin material slowly strained in tension nor was it seen in the granular fresh-water ice. It occurred here, we suggest, because of sliding along the boundaries of freshly created small grains which formed in pockets (Fig. 3), as the result of dynamic recrystallization during the precompression. Unfortunately, owing to the crumbling of the ice, it was not possible to obtain a thin section near a void-like crack.

The origin of the enhanced ductility of the columnar, saline ice is probably similar to the origin of the increased ductility of the granular, fresh-water material. As discussed earlier (Schulson and Kuehn, 1993) and in accord with Frost and Ashby's (1982) deformation map

Fig. 3. Thin section of the specimen shown in Figure $2 b . \quad \square$ Note the localized regions of recrystallized grains (squares).

(The numerical scale on the ruler is in centimeters.)

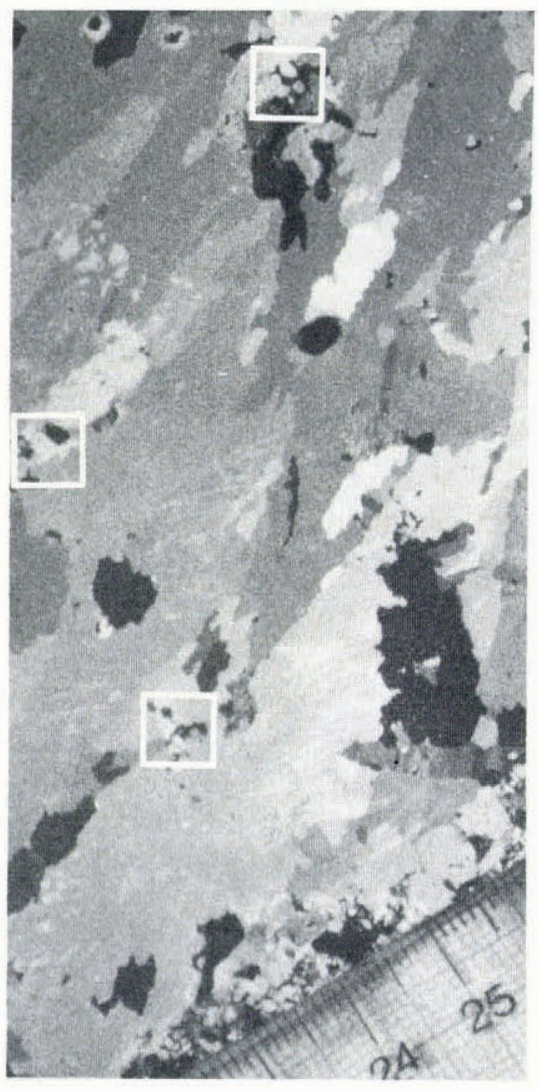


for ice, the creation of at least some relatively small, recrystallized grains during the pre-compression step probably allows diffusion creep to contribute to the overall inelastic deformation during the subsequent lowrate, tensile deformation. Indeed, the textured fracture surface and the fact that the largest elongation occurred at the lower strain rate support this view. Thus, the enhancement probably reflects the operation of two independent deformation mechanisms, the other one being dislocation creep. The global ductility of the saline ice was less than that of the fresh-water ice, because a smaller fraction of the matrix recrystallized and the recrystallization occurred less uniformly. The localized plastic strain, however, may have been similar.

An implication of the above observations concerns the structure and the behavior of a cover of first-year, columnar sea ice. Under some loading conditions, ice sufficiently thick to resist buckling may compress sufficiently slowly and to a sufficiently large degree to allow localized recrystallization. Even ice as cold as $-40^{\circ} \mathrm{C}$ may recrystallize upon slowly compressing by about $1 \%$, judging from the behavior of saline ice in the laboratory (Kuehn and Schulson, 1994). The change in microstructure would then not be restricted to the warmer parts of the cover. As a result, the feature may display mechanical behavior different from that of a virgin cover. In particular, provided that large cracks do not intervene by propagating, the cover may be capable of extending plastically under a slowly applied tensile stress. Whether this scenario actually occurs is not known.
In conclusion, experiments have shown that significant tensile ductility can be imparted to columnar, saline ice by first pre-compressing the material. This effect mirrors that reported earlier for granular fresh-water ice and is attributed to the operation of both diffusion creep and dislocation creep.

\section{ACKNOWLEDGEMENT}

This work was supported by the U.S. Office of Naval Research, contract No. N00014-92-J-1279.

\section{REFERENCES}

Frost, H.J. and M.F. Ashby. 1982. Deformation mechanism maps. Oxford, etc., Pergamon Press.

Kuehn, G. A. and E. M. Schulson. 1994. The mechanical properties of saline ice under uniaxial compression. Ann. Glaciol., 19, 39-48.

Kuehn, G. A., R. W. Lee, W. A. Nixon and E. M. Schulson. 1990. The structure and tensile behavior of first-year sea ice and laboratorygrown saline ice. 7. Offshore Mech. Arct. Eng., 112, 357-363.

Lee, R.W. 1986. A procedure for testing cored ice under uniaxial tension. F. Glaciol., 32(112), 540-541.

Schulson, E. M. and G. A. Kuehn. 1993. Ductile ice. Philos. Mag. Lett., 67(3), 151-157.

Smith, T.R. and E. M. Schulson. 1994. Brittle compressive failure of saltwater columnar ice under biaxial loading. F. Glaciol., 40(135), 265-276.

The accuracy of references in the text and in this list is the responsibility of the authors, to whom queries should be addressed. 